LA-UR-

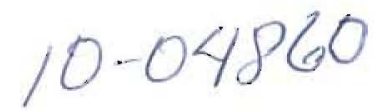

Approved for public release;

distribution is unlimited.

Title:

PROBLEMS WITH PACKAGED SOURCES IN FOREIGN COUNTRIES

\author{
Author(s): Abeyta, Cristy L. \\ Matzke, James L. \\ Zarling, John \\ Tompkins, J. Andrew \\ Intended for: \\ PATRAM 2010 Conference
ICEM 2010 Conference
}

Los Alamos National Laboratory, an affirmative action/equal opportunity employer, is operated by the Los Alamos National Security, LLC for the National Nuclear Security Administration of the U.S. Department of Energy under contract DE-AC52-06NA25396. By acceptance of this article, the publisher recognizes that the U.S. Government retains a nonexclusive, royalty-free license to publish or reproduce the published form of this contribution, or to allow others to do so, for U.S. Government purposes. Los Alamos National Laboratory requests that the publisher identify this article as work performed under the auspices of the U.S. Department of Energy. Los Alamos National Laboratory strongly supports academic freedom and a researcher's right to publish; as an institution, however, the Laboratory does not endorse the viewpoint of a publication or guarantee its technical correctness. 


\title{
PROBLEMS WITH PACKAGED SOURCES IN FOREIGN COUNTRIES
}

\author{
Cristy Abeyta, Jim Matzke, John Zarling and J. Andrew Tompkins \\ Los Alamos National Laboratory, Los Alamos, NM, USA
}

\begin{abstract}
The Global Threat Reduction Initiative's (GTRI) Off-Site Source Recovery Project (OSRP), which is administered by the Los Alamos National Laboratory (LANL), removes excess, unwanted, abandoned, or orphan radioactive sealed sources that pose a potential threat to national security, public health, and safety. In total, GTRI/OSRP has been able to recover more than 25,000 excess and unwanted sealed sources from over 825 sites. In addition to transuranic sources, the GTRI/OSRP mission now includes recovery of beta/gamma emitting sources, which are of concern to both the U.S. government and the International Atomic Energy Agency (IAEA). This paper provides a synopsis of cooperative efforts in foreign countries to remove excess and unwanted sealed sources by discussing three topical areas: 1) The Regional Partnership with the International Atomic Energy Agency; 2) Challenges in repatriating sealed sources; and 3) Options for repatriating sealed sources.
\end{abstract}

\section{INTRODUCTION}

The OSRP under GTRI, recovers and manages excess and unwanted radioactive sealed sources that present a potential threat to national security, public health, and safety. Since 1999, GTRI/OSRP has been able to recover more than 25,000 sources from over 825 sites (including all 50 states, the D.C. area, Puerto Rico and a number of foreign countries). The program scope addresses isotopes that present substantial safety and security risks. GTRI is now implementing international sealed source repatriation, on a case-by-case basis, as an alternative option to physical security upgrades at waste storage facilities.

Radioactive sources are used in medical, industrial, agricultural, academic, and government facilities for a variety of purposes. Since the 1960s, radioactive sealed sources have been provided to institutions worldwide by the U.S. Government and American companies to promote the peaceful uses of nuclear technology. Additionally, private companies have sold and/or donated radioactive sealed sources and source-containing devices in commerce. In the U.S., radiological sealed sources are placed in a storage facility, pending disposal, when they are no longer needed.

In many countries, radiological sealed sources have been abandoned or are placed in facilities that are often improperly maintained and poorly guarded. These types of sealed sources could be potentially stolen and used for malicious purposes. Radioactive materials are scattered across the world at thousands of sites, and hundreds of them contain enough radioactive material for a "dirty bomb". Small amounts of radioactive materials have gone missing and many never have been accounted for. 


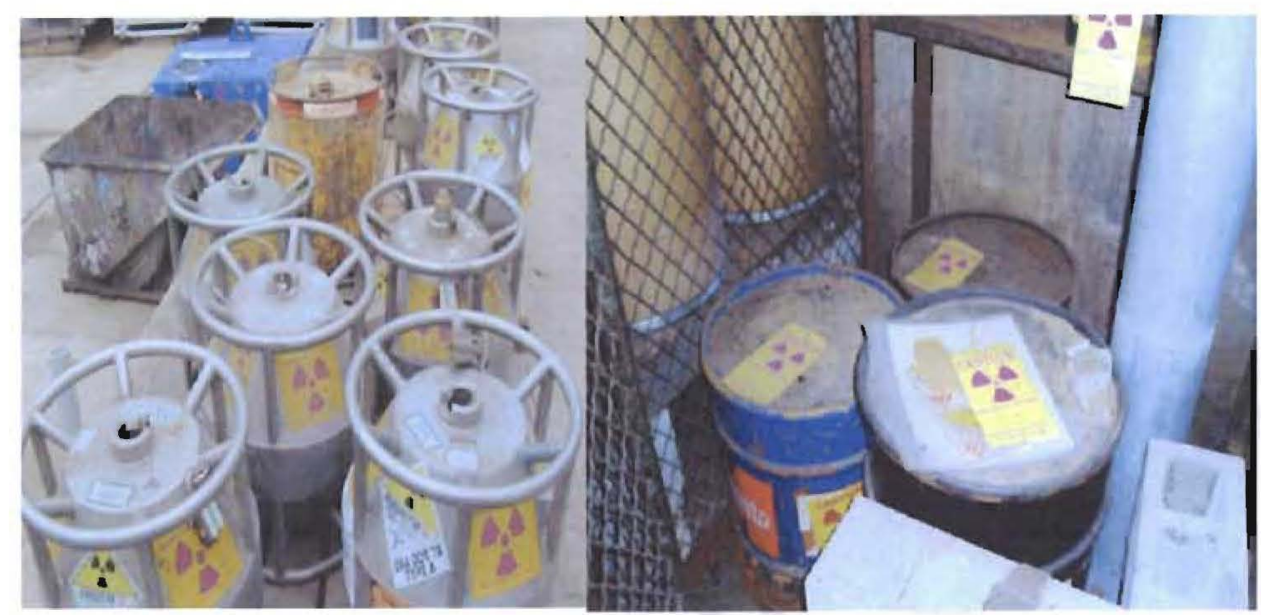

Figure 1: Disused and Unwanted sources

Currently, there are tens of thousands of locations worldwide with radioactive material. Large amounts of radioactive materials are used daily in medicine, industry and research include:

Americium 241: Low activity (micro-millicuries) are used in smoke detectors and lighting arrestors, and nuclear gauging applications. Higher activities (3-16 Ci) sources are used in the petroleum exploration industry.

Cesium 137: Used to treat cancers, measure and control the bulk and liquid flowrates, and to irradiated whole blood.

Cobalt 60: Used in industrial radiography and to sterilize medical supplies and instruments. Also used in large industrial irradiators.

Iridium 192: Used to radiograph pipeline welds, boilers, steam generators, and gas turbine parts for Non Destructive Testing quality control.

Plutonium 238: Used to power at least 20 NASA spacecraft since 1972, 1900 nuclear pacemakers, and other applications where a long lived no electrical power heat source is of value.

Plutonium 239: Used in nuclear weapons and in the original small compact neutron sources developed in the 50 s and 60's.

Radium-226: Radium is the most ubiquitous of the isotopic medical sealed sources worldwide. Hundreds of these small (5-15 mgram) sources exist in every country on earth.

Over the last year, several countries were identified for repatriation exercises and have requested assistance GTRI/NNSA to remove these radioactive sealed sources. These governments have no disposal pathway for these sealed sources. Bilateral and multilateral operations have already been carried out successfully, thus demonstrating the value and feasibility of cooperating internationally in this new effort. 


\section{REGIONAL PARTNERSHIP WITH THE INTERNATIONAL ATOMIC ENERGY AGENCY}

GTRI has joined with the IAEA and the U.S. Department of State (DOS) in a Regional Partnership in South America to identify, condition, and dispose of disused and unwanted radioactive sealed sources. This activity is funded by the Nonproliferation and Disarmament Fund (NDF) at the DOS, as well as in-kind contributions from NNSA/GTRI. The scope of the South American regional partnership is intended to address radioactive sealed sources in five countries: Argentina, Brazil, Colombia, Uruguay, and Venezuela. The NDF project implementation is coordinated under the IAEA Division of Nuclear Fuel Cycle and Waste Technology and the IAEA Office of Nuclear Security. The Latin American Regional Partnership is a pilot program to reduce the number of unwanted and disused radioactive sealed sources that could be used by terrorists for malicious purposes, such as a Radioactive Dispersion Device (RDD), "dirty bomb".

Since May 2005, GTRI/OSRP has recovered 932 sources from 18 international sites. Table 1 list the countries, number of radioactive sealed sources and total activity recovered by GTRI/OSRP. GTRI/OSRP is also involved in training workshops in support of NINSA/GTRI Search and Secure or IAEA Regional support Teams. NNSA/GTRI has also initiated bilateral cooperation to recover disused and unwanted sources from other countries outside the NDF project.

Table 1: Countries number of Sealed Sources Recovered by GTRI/OSRP

\begin{tabular}{|l|r|r|}
\hline \multicolumn{1}{|c|}{ Country } & \multicolumn{1}{c|}{$\begin{array}{c}\text { Number of } \\
\text { Sources }\end{array}$} & \multicolumn{2}{c|}{$\begin{array}{c}\text { Total } \\
\text { Activity (Ci) }\end{array}$} \\
\hline Argentina & 19 & 47.5 \\
Australia & 207 & 48.5 \\
Brazil & 127 & 170.3 \\
Canada & 3 & 2.4 \\
Chile & 431 & 26.7 \\
Denmark & 11 & 43.5 \\
Ecuador & 36 & 8.5 \\
Israel & 7 & 29.0 \\
Italy & 11 & 1209 \\
\hline Singapore & 1 & $5 \mathrm{E}-3$ \\
South Africa & 69 & 22.67 \\
Sweden & 9 & 19.1 \\
Uruguay & 2 & $9 \mathrm{E}-06$
\end{tabular}

\footnotetext{
${ }^{1}$ OSRP also supported IAEA recovery of Co-60 and Cs-137 in an international recovery effort for old teletherapy heads.

NOTE: In May 2005, the GTRI/OSRP team traveled to Uruguay and packaged 3 sources. At this time, only 2 of the sources were eligible for air transport and have been returned to the US.
} 


\section{CHALLENGES IN REPATRIATING SEALED SOURCES}

\section{Transportation Challenges:}

Many of the sources outside of the U.S. cannot be considered special form, as defined in 49 CFR 403. These sealed sources must either be transported in a Type B package as normal form or conditioned to meet special form criteria and transported in a Type A or Type $A$ Fissile package.

Type B packaging is expensive and very specific to the content it can contain. Many Type B packages would require content modifications to allow for the different types of sealed sources GTRI/OSRP recovers. Also each country's Competent Authority prior to shipment must approve these packages as well as all other countries the material will pass through. The time required by each country's Competent Authority to approve the container for shipment varies.

In order to address the conditioning to meet special form criteria challenge, the GTRI/OSRP developed a sealed source capsule to meet special form as defined by 10 CFR 71.75. Radioactive sealed sources in special form can be transported in DOT Type A containers in quantities up to the $A_{1}$ limit reported in 49 CFR $173.435^{3}$. For isotopes of particular interest to the OSR Project, i.e., plutonium (Pu)-238, Pu-239 and americium (Am)-241, the $A_{1}$ limit (special form) is 10,000 times greater than the $A_{2}$ limit (normal form). The special form capsules can be easily sealed and are fabricated in various sizes to accommodate most physical sizes and isotopic range of sealed sources likely to be encountered. Again, the Type A Fissile package must be approved by each country's Competent Authority prior to shipment and all other countries the material will pass through.

An alternative to approval of the package is special arrangement. Special arrangement must be approved by each country's Competent Authority prior to shipment in the country of the recovered sources and all other countries the material must pass through. The time required by each country's Competent Authority to approve the special arrangement varies.

\section{Scheduling conflicts:}

In May 2005, the GTRI/OSRP team traveled to Uruguay and packaged 3 sources. At this time 2 of the sealed sources packaged, which were eligible for air transport, have been returned to the U.S. One packaged drum containing Pu239, will remain in Uruguay until the drum can be placed with a future shipment of spent nuclear fuel from the region. An opportunity to move this drum from Uruguay to another country to be shipped on a spent fuel shipment was missed. Arrangements to move the drum to the spent fuel shipment were not completed in time. Denial of shipment also exists since this $80 \mathrm{~g}$ PuBe source falls within the realm of 49 CFR 173 UN3333 Fissile shipping requirements.

Sources in another country were delayed due to the liability of ownership determination between the country and U.S. governments. Another country had a delay due to lack of funding of the facility to ship the source at an earlier date. All of the materials missed a potential shipment due to a lack of validation of a Type A Fissile container by a country that 
the sources had to pass through to reach port for the fuel shipment. Revalidation of Type $A$ containers or a CoCA seems like a minor problem until a foreign transportation entity stops the shipment due to their need to review all of the package documentation.

\section{Shipments by air:}

Shipping sealed sources by air is ideal for most recovery operations and can be readily accomplished. However, regulations regarding air shipment of plutonium into and within the U.S. are highly restrictive and are not harmonized with international regulations.

Transporting plutonium by air into or within the U.S. can only be legally conducted after qualifying under the following two exemptions: 1) 10 CFR 871.1., National Security reasons; or 2) 10 CFR 871.1.2, Public Health and Safety reasons. This requires GTRI/OSRP program to repatriate plutonium sources by utilizing ocean vessels only ${ }^{2}$.

Additional challenges to air transportation include package testing requirements and lack of certification for containers. For example, Type AF packages certified for air transport outside the U.S. are not certified for air transport into or within the U. S. without additional testing. While the GTRI/OSRP will continue to pursue certifications for containers, any air shipment of plutonium will still require an exemption under 10 CFR 871.

\section{Denial of Shipment:}

Another challenge that is faced is denial of shipment by carriers. Denials of shipment still occur, despite all the mechanisms for ensuring special form, which directly prevents moving at-risk sources from unsecured storage areas to safe and protected locations. For example, carriers maintain authority to choose their cargo and will often refuse to carry these types of materials. Additionally, carriers will refuse based on risks of higher costs or they may not have the experience needed to transport radioactive material, Class 7 cargo, especially fissile material. Likewise, countries and individual ports may refuse in-transit shipments or issue severe restrictions and/or fees to control the Class 7 cargo. GTRI/OSRP depends on successful transportation of radioactive material for the return of U.S.-origin sealed sources from foreign locations. It is essential to have a reliable means to return vulnerable at risk radioactive sealed sources to a safe and secure environments.

\section{Developing pathways for disposition of non-US-origin material:}

Currently, NNSA/GTRI is repatriating U.S.-origin materials either bilaterally or multilaterally from countries in which they have no disposal pathway or other suitable disposition options. Some radiological sealed sources in foreign countries are not of U.S.-origin. Devices from other manufacturing countries such as Canada, France, and India have also been found. Generally, these countries are willing to repatriate material, but the associated costs are prohibitive given the amount of activity that requires management.

\section{Management of high-activity sealed sources:}

\footnotetext{
${ }^{2}$ This is not as great a problem for Mexico or Canada since road freight shipments are possible
} 
One of the biggest problems in the South American region is the lack of options for management of high-activity sealed sources and source-containing devices that require Type B packages for transportation. Type B packages are very expensive to use and alternatives have limitations such as; disposing of material in place, removing sources from devices and transporting only the sources, and developing less expensive Type B containers. GTRI/OSRP has been focused on its own efforts to support lower-cost alternative Type B package certification.

Domestically, GTRI/OSRP has used DOT Specification 6M and 20WC containers for a multitude of disused sealed source recovery operations involving Type B quantities of radioactive sources. Type $\mathrm{B}$ quantity is when any sealed source exceeds the promulgated $A_{1}$ and $A_{2}$ values for special form and normal form. Unfortunately, due to changes in US transportaion regulations, US DOT Specification Type B packages expired on October 1 , 2008.

If a disused source meets the definition of special form but exceeds the $A_{1}$ value, it can only be transported in a Type B package. Typically, Type B packages are in short supply, very difficult to use, they require specialized equipment such as cranes, and are extremely expensive to use, especially for long shipping times that may be incurred in boat shipments.

GTRI/OSRP will continue to work to find ways to accelerate the recovery of high-activity source-containing devices such as $\mathrm{CsCl}$ irradiators and $\mathrm{Co} 60$ teletherapy. In the prioritization scheme agreed with NRC, high-activity source-containing devices are generally high on the list, so GTRI/OSRP is taking several actions to address recovery barriers, including the shortage of certified Type B containers.

\section{OPTIONS FOR REPATRIATING SEALED SOURCES}

The GTRI/OSRP has provided funding to a private company, to include our content, in the development of a replacement container for the DOT Specification 20WC packages. This new Type B package will be known as the Model BU-650. Once the design is tested, a Type $B$ Certificate of Conformance ( $\mathrm{CoC}$ ) must be obtained from the U.S. NRC. When approved, the GTRI/OSRP plans to become a registered user.

GTRI/OSRP has contracted for the development of a new Type B package which would be used as a replacement for 20WC-type packaging. According to public statements by the NRC, new Type B package development and certification can take several years. Completion of the final design and submittal for certification of the new GTRI/OSRP Type B design is not expected to be completed until late 2011. Even after development and certification by the regulatory authority, fabrication and procurement of new 20WC-replacement containers is anticipated to take an additional year. The 20WC replacement packaging being developed by GTRI/OSRP will not be available for source recovery operations prior to the proposed June 30, 2012 expiration of this special permit. Therefore, this conscientious request is made to ensure that GTRI/OSRP can continue source recovery operations for threat reduction purposes during this period. 


\section{FOREIGN ORIGIN TRU SEALED SOURCES}

Since the depletion of US stockpiles of Americium (Am)-241 (2005), US companies have been importing Russian origin high activityAm-241 source material. Since Russia does not allow the return of sources that originate within their country, the US will eventually have to develop the capability to dispose of Russian transuranic (TRU) sealed sources. One logical path for this activity is to develop a WIPP Defense Determination for Russian origin TRU sealed. NNSA is currently considering its options for this disposition pathway.
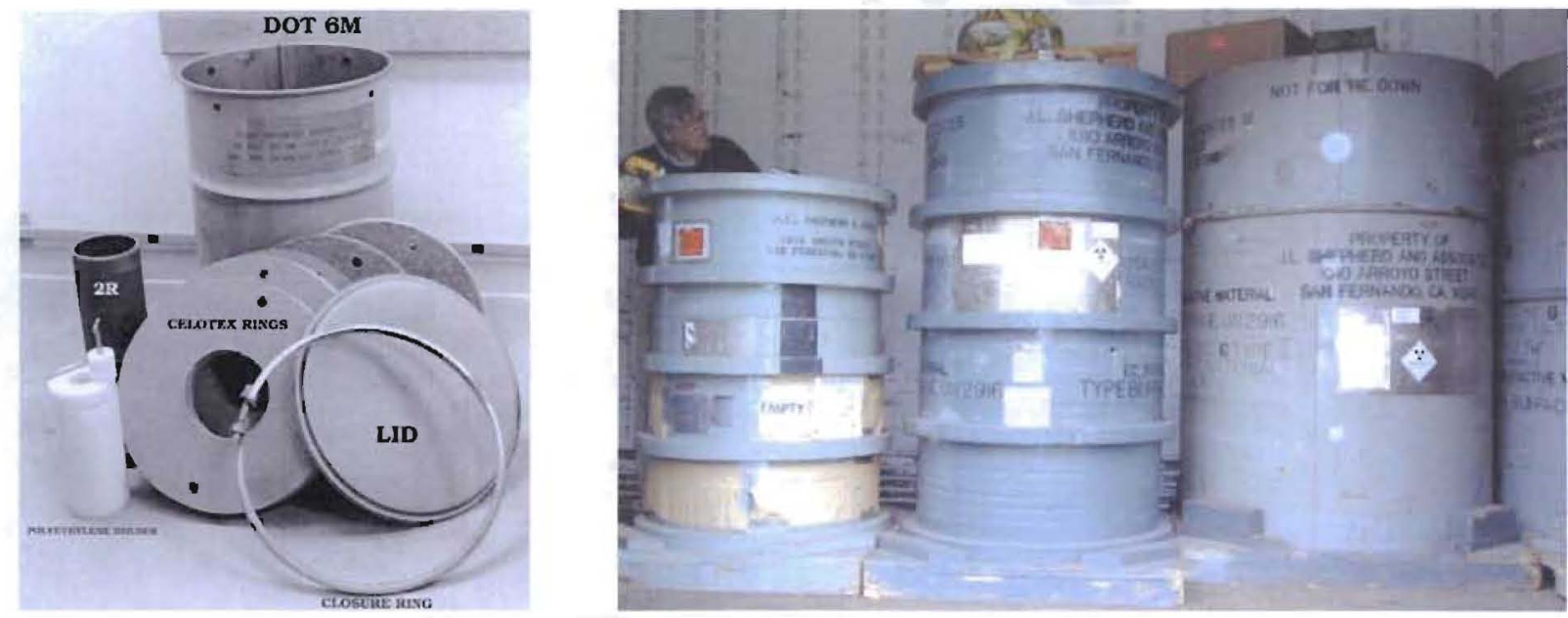

Figure 2: Examples of DOT 6M Package \& 20WC Containers

GTRI/OSRP has also developed three variations of a multifunction container called a POC (Pipe Overpack Component) to satisfy requirements for U.S. Department of Transportation (DOT) 7A Type A containers. These containers also qualify for use in the TRUPACT II overpack used to transport material to the Waste Isolation Pilot Plant (WIPP) in Carlsbad, N.M. and serve as interim storage and final disposition containers. The multi function nature of these packages is intended to minimize repeat handling and packaging of sealed sources. The complication of the multifunction container is maintaining approval of the US NRC, DOT, and DOE/NNSA WIPP requirements.

\section{CONCLUSION}


GTRI/OSRP will continue to work to find ways to accelerate the recovery of high-activity sources. GTRI/OSRP is working to address recovery barriers ${ }^{3}$, including the shortage of certified Type B packages, transfer casks, and well shielded portable hot cells for remote manipulation of these high activity sources.

GTRI/OSRP will also continue to work to remove disposal barriers previously discussed, as well as developing disposition pathways for $\mathrm{Cm}-244$, Cf-252, and Np-237 sources, and other types of sources it has already recovered to support threat reduction missions. GTRI/OSRP's support for the DHS-chaired interagency focus group on disposal will continue to search for solutions to the lack of commercial disposal capacity that is creating national security concerns within the US.

\section{REFERENCES}

1. D. Eisenhower, Address to the United Nations, December 1953.

2. IAEA, "Proceedings of the International Conference on Security of Radioactive Sources," Vienna, Austria, September 2003 (as cited in GAO-05-967).

3. Government Accounting Office, "DOE Needs Better Information to Guide Its Expanded Recovery of Radiological Sealed Sources," GAO-05-967, September 2005.

4. L. Leonard et al, "The Offsite Source Recovery Project at Los Alamos National Laboratory," LA-UR-99-6218, TWCP-03756, 1999.

5. Government Accounting Office, "DOE Action Needed to Ensure Continue Recover of Unwanted Sealed Radioactive Sources," GAO-03-483, April 2003.

6. U.S. Department of Energy, "Site-Wide Environmental Impact Statement for Continued Operation of the Los Alamos National Laboratory," Vol. Summary, DOE/EIS-0238, Albuquerque, NM, January 1990.

7. DOE/NRC Interagency Working Group on Radiological Dispersal Devices, Radiological Dispersal Devices: An Initial Study to Identify Materials of Greatest Concern and Approaches to Their Tracking, Tagging and Disposal (May 2003).

8. National Academy of Sciences, "Radiation Source Use and Replacement," National Academies Press, 2008.

9. OSRP Monthly Report, May, 2010.

\footnotetext{
${ }^{3}$ Health Physics Society, Discussion paper, Actions Needed to Better Secure Vulnerable Radioactive Sources: A Contemporary Report Prepared by a Working Group of the Health Physics Society, Sept 2005 ",
} 